\title{
Effective treatment of TNFa inhibitors in Chinese patients with Blau syndrome
}

\author{
Jing Chen ${ }^{1,2+}$, Yi Luo $^{1+}$, Mengzhu Zhao ${ }^{1}$, Di Wu' , Yunjiao Yang ${ }^{1}$, Wen Zhang ${ }^{1}$ and Min Shen ${ }^{1,3^{*}}$
}

\begin{abstract}
Objectives: Blau syndrome (BS) is a rare dominantly inherited autoinflammatory disorder associated with mutations in the nucleotide-binding oligomerization domain containing 2 (NOD2) gene. Biologic therapy of BS yielded diverse results. We aimed to evaluate clinical features and outcomes of Chinese patients with BS who were treated with tumor necrosis factor (TNF)a inhibitors.

Methods: A total of four patients with BS were diagnosed and treated with infliximab (IFX) at the Peking Union Medical College Hospital during 2015 to 2018 and were followed up for 18 months. All patients were systematically studied for treatment outcomes including the clinical manifestations and inflammatory markers. We also conducted a comprehensive literature review about TNFa inhibitor therapy in BS.

Results: Four BS patients were all Chinese Han, and three were women. The mean age of disease onset was $4 \pm$ 3.5 years, and the mean time of diagnosis delay was $19 \pm 11$ years. All patients received IFX plus methotrexate, and all achieved clinical remission of skin lesions and polyarthritis rapidly, as well as normalization of erythrocyte sedimentation rate and C-reactive protein and improvements in inflammatory cytokines, patient visual analogue scale, physician global assessment, and Short Form (SF)-36, at the first follow-up of 6 months. The disease relapsed in two patients after they lengthened the interval of IFX and discontinued methotrexate. According to the 38 English-language publications, 62 patients with BS were reported who underwent TNFa inhibitor therapy, including IFX used in 31, adalimumab in 24, and etanercept in 7. IFX was well tolerated in 27 patients, while 2 still had uveitis, and the other 2 experienced an adverse drug reaction.
\end{abstract}

Conclusions: Early recognition and effective treatment of BS are very important to avoid irreversible organ damage. TNFa inhibitors such as IFX may be a promising approach for BS patients who have unsatisfactory response to corticosteroids and traditional disease-modifying antirheumatic drugs.

Keywords: Systemic autoinflammatory diseases, Nucleotide-binding oligomerization domain, Blau syndrome, TNFa inhibitors

\section{Introduction}

Blau syndrome (BS; OMIM 186580) is a rare dominantly inherited autoinflammatory disorder [1], associated with mutations in the nucleotide-binding oligomerization domain containing 2 (NOD2) gene [2]. The main features of BS include the clinical triad of granulomatous dermatitis,

\footnotetext{
* Correspondence: shenmpumch@163.com

${ }^{+}$Jing Chen and Yi Luo contributed equally to this work.

'Department of Rheumatology, Peking Union Medical College Hospital, Chinese Academy of Medical Sciences \& Peking Union Medical College, Key Laboratory of Rheumatology and Clinical Immunology, Ministry of Education, Beijing 100730, China

${ }^{3}$ Department of Rheumatology, Peking Union Medical College Hospital, No.1 Shuaifuyuan, Dongcheng District, Beijing 100730, China

Full list of author information is available at the end of the article
}

arthritis, and recurrent uveitis with childhood onset [3]. BS is mainly seen in Caucasian patients [4,5], but has also been sparsely reported in the Chinese population $[6,7]$. We have documented the two by far the largest Chinese pedigrees with 13 members affected [8]. The heterozygous R334W variant in the NOD2 gene was identified in both families. The considerable percentage of patients who had only one component of the classical triad further complicates the diagnosis of $\mathrm{BS}$ in clinical practice.

It is critical to control the eye and joint involvements to improve the prognosis of BS. The use of non-steroid anti-inflammatory drugs (NSAIDs), corticosteroids, and in refractory cases, immunosuppressive agents, such as

(C) The Author(s). 2019 Open Access This article is distributed under the terms of the Creative Commons Attribution 4.0 International License (http://creativecommons.org/licenses/by/4.0/), which permits unrestricted use, distribution, and 
methotrexate and azathioprine, has been reported to date. Recently, biologic agents such as interleukin (IL)-1 blockers and tumor necrosis factor (TNF) $\alpha$ inhibitors have demonstrated promising effects in some cases of unsatisfactory response $[9,10]$. We have reported a 13year-old Chinese boy with refractory BS who maintained an effective response to tocilizumab [7]. After a systematic literature review, we found that biologic therapy of BS yielded diverse results [7], which may be due to the different genotypes and phenotypes of BS. Meanwhile, the small number of patients in those studies may also make it difficult to give a definite conclusion.

In this study, we describe four Chinese patients with BS who were treated with infliximab (IFX) during 2015 to 2018, in Peking Union Medical College Hospital, and also reviewed the published English literature of TNFa inhibitor therapy in this disease.

\section{Patients and methods}

All these four Chinese BS patients were referred to and followed up for 18 months in our tertiary medical center, including three patients we have reported before [8]. Complete medical records and detailed data were collected and documented. Due to unavailability of IL-1 antagonist therapies in China, they were treated with IFX. We assessed the response to therapy by monitoring inflammatory markers, which include white blood cell count (WBC), Creactive protein (CRP), erythrocyte sedimentation rate (ESR), and TNF $\alpha$, IL-1 $\beta$, and IL-6 levels, and observing clinical manifestations by patient visual analogue scale (VAS), physician global assessment (PGA), and Short Form (SF)-36. We performed a systematic literature search in PubMed using the terms as "Blau syndrome" OR "autoinflammatory disease AND TNFa inhibitors" OR "Blau syndrome AND TNF $\alpha$ inhibitors" OR "Blau syndrome AND infliximab." Totally, there were 249 articles published in PubMed ranging from September 1991 to March 2019, of which 203 articles were excluded for not reporting TNF $\alpha$ inhibitors used in BS. Among the remaining 46 articles, the full texts of 8 articles were unavailable. Ultimately, 38 articles containing case reports of BS patients receiving the treatment modalities were reviewed.

This research was approved by the Institutional Review Board of Peking Union Medical College Hospital and performed according to the Declaration of Helsinki. Informed consents were obtained from all participants. Whole exome sequencing by next-generation sequencing was performed in the Center for Genetic Testing, Joy Orient Translational Medicine Research Centre Co., Ltd., Beijing, China.

\section{Results}

The demographic data, clinical phenotypes, and laboratory features of these four patients were summarized in
Table 1. The mean age of disease onset was $4 \pm 3.5$ years. The mean age at diagnosis was $22 \pm 14$ years, and the mean time of diagnosis delay was $19 \pm 11$ years.

\section{Patient 1}

A 32-year-old Chinese Han woman presented with dermatitis, arthritis, uveitis, and intermittent fever for 26 years. She had chronic polyarthritis involving bilateral joints of the hands, wrists, elbows, knees, and ankles since the age of 6, which resulted in camptodactyly (Fig. 1a). She also developed persistent bilateral panuveitis since the age of 12 , which caused atrophy of both eyeballs and eventually complete loss of vision. She had papular rashes on extremities and intermittent fever. She had a family history of similar symptoms (Fig. 1d). A heterozygous R334W variant in the NOD2 gene was identified and the diagnosis of $\mathrm{BS}$ was confirmed. Combination treatment of corticosteroids and disease-modifying antirheumatic drugs (DMARDs) such as methotrexate, leflunomide, and cyclosporine over 5 years had no effect. Laboratory evaluation of disease activity at diagnosis is shown in Table 1. She was treated with IFX (5 $\mathrm{mg} / \mathrm{kg}$ ) every 6 to 8 weeks at the beginning plus methotrexate $15 \mathrm{mg}$ every week, with a satisfactory response for the polyarthritis and dermatitis. ESR and CRP rapidly decreased to normal levels after therapy. After 6 months, IFX was changed to $5 \mathrm{mg} / \mathrm{kg}$ every 12 weeks plus methotrexate 12.5 $\mathrm{mg}$ every week. At the last follow-up after IFX therapy of 18 months, her disease maintained stable (Fig. 2).

\section{Patient 2}

This 8-year-old Chinese Han boy was the son of patient 1. He suffered from polyarthritis and papules on his four limbs at 6 months after birth and gradually developed camptodactyly (Fig. 1b, c) without uveitis or fever. He was treated with IFX $(5 \mathrm{mg} / \mathrm{kg})$ every 8 weeks plus methotrexate $10 \mathrm{mg}$ every week, and the symptoms relieved rapidly (Fig. 2). At 18-month follow-up, he was symptom-free, and IFX was continued every 12-16 weeks.

\section{Patient 3}

A 36-year-old Chinese Han woman complained of uveitis, dermatitis, and arthritis for nearly 30 years. She had chronic bilateral panuveitis since the age of 7 , which led to blindness 7 years later. She suffered from widespread intermittent erythematous maculopapular rash since the disease onset. She also developed persistent polyarthritis since the age of 13, without obvious deformity. She had a positive family history of BS (Fig. 1e). Genetic testing identified a heterozygous NOD2 R334W variant. The patient only received irregular NSAIDs for her arthritis with partial relief. ESR and CRP were elevated at baseline (Table 1$)$. She received IFX ( $5 \mathrm{mg} / \mathrm{kg}$ ) every 6 to 8 weeks plus methotrexate $15 \mathrm{mg}$ every week. Polyarthritis 
Table 1 Demographic and clinical features of four Chinese patients with BS

\begin{tabular}{|c|c|c|c|c|}
\hline Patients & 1 & 2 & 3 & 4 \\
\hline Gender & Female & Male & Female & Female \\
\hline $\begin{array}{l}\text { Age at } \\
\text { diagnosis } \\
\text { (years) }\end{array}$ & 32 & 8 & 36 & 25 \\
\hline $\begin{array}{l}\text { Age at onset } \\
\text { (years) }\end{array}$ & 6 & 0.5 & 7 & 6 \\
\hline Ethnicity & Han & Han & Han & Han \\
\hline Family history & + & + & + & - \\
\hline \multicolumn{5}{|l|}{ Clinical features } \\
\hline Joint & + & + & + & + \\
\hline Skin & + & + & + & - \\
\hline Eye & + & - & + & + \\
\hline Fever & + & - & - & - \\
\hline NOD2 variants & R334W & R334W & R334W & R334Q \\
\hline \multicolumn{5}{|c|}{ Laboratory findings } \\
\hline $\begin{array}{l}\text { WBC }\left(\times 10^{9} /\right. \\
\mathrm{L})\end{array}$ & 4.15 & 9.5 & 16.3 & 7.99 \\
\hline CRP (mg/L) & 3.48 & 20.0 & 33.01 & 3.4 \\
\hline ESR $(\mathrm{mm} / \mathrm{h})$ & 16 & 5 & 48 & 11 \\
\hline $\begin{array}{l}\mathrm{IL}-1 \beta(\mathrm{pg} / \\
\mathrm{ml})\end{array}$ & 78.0 & 77.8 & 70.2 & 108.5 \\
\hline $\begin{array}{l}\text { TNFa (pg/ } \\
\mathrm{ml})\end{array}$ & 114.0 & 245.0 & 156.2 & 174.0 \\
\hline IL-6 (pg/ml) & 104.0 & 111.0 & 66.7 & 68.0 \\
\hline VAS & 10 & 10 & 7 & 5 \\
\hline PGA & 8 & 5 & 5 & 5 \\
\hline SF-36 & 49.31 & 61.81 & 43 & 46.25 \\
\hline \multicolumn{5}{|l|}{ Treatment } \\
\hline IFX & $\begin{array}{l}5 \mathrm{mg} / \mathrm{kg} \text { every } 6-8 \text { weeks for } 6 \text { months/ } \\
5 \mathrm{mg} / \mathrm{kg} \text { every } 12 \text { weeks }\end{array}$ & $\begin{array}{l}5 \mathrm{mg} / \mathrm{kg} \\
\text { every } 8 \\
\text { weeks }\end{array}$ & $\begin{array}{l}5 \mathrm{mg} / \mathrm{kg} \text { every } 6-8 \text { weeks for } 6 \\
\text { months } / 5 \mathrm{mg} / \mathrm{kg} \text { every } 12 \text { weeks }\end{array}$ & $\begin{array}{l}3 \mathrm{mg} / \mathrm{kg} \text { every } 8 \text { weeks for } 6 \text { months/ } \\
3 \mathrm{mg} / \mathrm{kg} \text { every } 12-16 \text { weeks }\end{array}$ \\
\hline MTX & $\begin{array}{l}15 \mathrm{mg} \text { weekly for } 6 \text { months/12.5 mg } \\
\text { weekly }\end{array}$ & $\begin{array}{l}10 \mathrm{mg} \\
\text { weekly }\end{array}$ & $\begin{array}{l}15 \mathrm{mg} \text { weekly for } 6 \text { months/ } \\
\text { discontinuation due to side effects }\end{array}$ & $\begin{array}{l}10 \mathrm{mg} \text { weekly for } 6 \text { months/ } \\
\text { discontinuation due to side effects }\end{array}$ \\
\hline Prednisone & Not used & Not used & Not used & $15 \mathrm{mg} /$ day tapered to $5 \mathrm{mg} /$ day \\
\hline
\end{tabular}

WBC white blood cells, CRP C-reactive protein, ESR erythrocyte sedimentation rate, VAS visual analogue scale, PGA physician global assessment, SF-36 Short Form36, IFX infliximab, MTX methotrexate

and dermatitis subsided rapidly, and the acute phase reactants decreased at a 6-month follow-up. But she stopped methotrexate because of severe gastrointestinal side effects, and IFX was tapered to every 12 weeks due to financial limitations. At 18 months, her symptoms relapsed (Fig. 2) and IFX was given every 8 weeks again.

\section{Patient 4}

A 25-year-old Chinese Han woman developed persistent polyarthritis since the age of 6 , involving bilateral joints of the hands and knees, and gradually developed interphalangeal joint flexion. At the age of 20, bilateral uveitis occurred and her vision gradually decreased. She had no dermatitis or fever. She denied family history of BS (Fig. 1f). A de novo heterozygous R334Q variant was identified in the NOD2 gene. Cyclosporine with prednisone had no effect for the polyarthritis and uveitis. IFX $(3 \mathrm{mg} / \mathrm{kg})$ every 8 weeks plus methotrexate $10 \mathrm{mg}$ every week was given. Her symptoms were well controlled at a 6-month follow-up, and prednisone was tapered from $15 \mathrm{mg}$ per day to $5 \mathrm{mg}$ per day. Methotrexate was stopped due to gastrointestinal side effects, and IFX was reduced to every 12-16 weeks since then, but the disease relapsed at her last follow-up at 18 months (Fig. 2). 


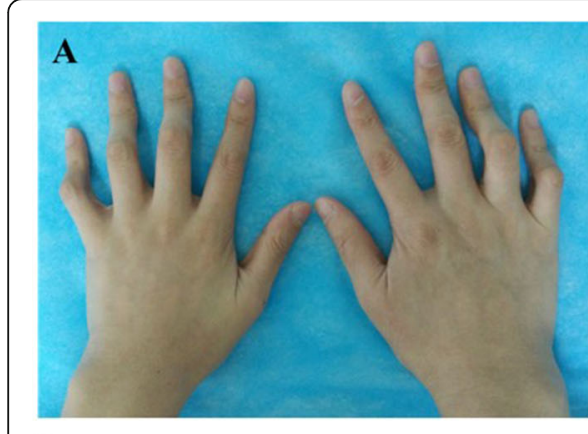

D

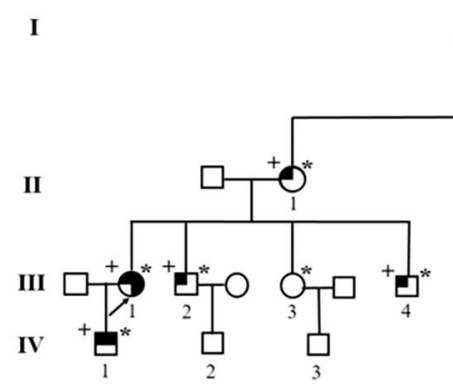

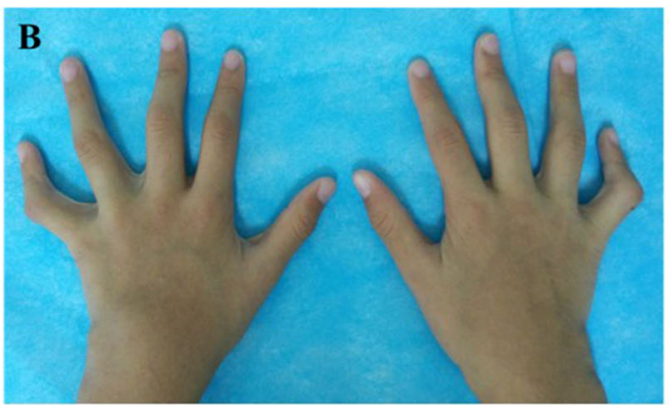

$\mathbf{E}$

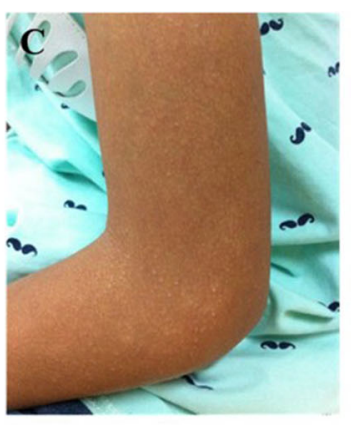

I
II

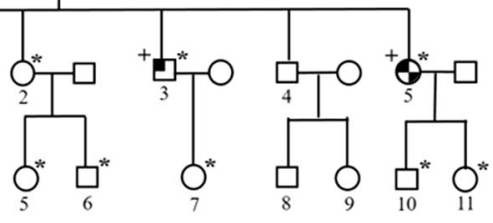
$\square \bigcirc$ Unaffected O Skin ras (1) Uveitis

Fig. 1 Pedigrees and phenotypes of Chinese patients with BS. Camptodactyly of patients 1 (a) and 2 (b); papules on the upper limbs of patient 2 (c); pedigrees of patients 1 and 2 (d), 3 (e), and 4 (f)

\section{Literature review}

According to the 38 English-language publications, 62 patients with BS were reported who underwent TNF $\alpha$ inhibitor therapy. Among the 62 patients, IFX was used in 31 patients, adalimumab in 24 , and etanercept in 7 . IFX was well tolerated in 27 patients [11-22], while 2 patients still had uveitis [7,23], and the other 2 experienced an adverse drug reaction to IFX infusion [21]. Adalimumab was useful in 21 BS patients [9, 14, 23-28], although the other 3 patients did not get well controlled $[21,29,30]$. Five BS patients who were given etanercept yielded good responses [9, 24, 31, 32], but 2 patients discontinued because of etanercept-induced myelopathy [33] or an exacerbation of arthritis [14].

\section{Discussion}

Since it is difficult to differential BS from other rheumatic diseases such as rheumatoid arthritis, juvenile idiopathic arthritis, and Behçet's disease, the diagnosis of BS is a great challenge to rheumatologists, especially in China. For instance, Behçet's disease can manifest as arthritis, dermatitis, and uveitis as well, although other heterogenic features including oral and genital ulcers, arterial aneurysms, venous and arterial thrombosis, central nervous system involvement, and intestinal ulcers are prominent, and there is no NOD2 gene mutation. Although there have been some reports of BS case series
[6-8], including ours, the incidence of BS in the Chinese population is still unclear. In this study, we found that the duration of diagnosis delay was approximately 20 years. It suggests there may be underdiagnoses of BS in the Chinese population. On the other hand, our previous research showed that the clinical manifestations of BS in Chinese were milder and incomplete compared with those in Caucasians [8]. Meanwhile, one of the patients in our study was a sporadic case with a de novo NOD2 variant. These findings suggest that BS should be considered and gene analysis should be promoted for patients with one or more manifestations among the clinical triad at disease onset, whether or not there is a family history.

Owing to the low incidence of BS, there have been no controlled clinical studies dealing with therapies for this disorder. Case series of BS concerning the treatments were mainly based on personal experience. High dose of glucocorticoids and immunosuppressants are effective in some patients, but the long-term use may cause severe side effects, especially to young patients. Moreover, immunosuppressants are ineffective in some BS patients and it may be difficult to reduce the dosage of steroids. As we know, NOD2 is an intracellular bacterial sensor protein of the NOD-like receptor (NLR) family which recognizes muramyl dipeptide (MDP), undergoes oligomerization, and interacts with receptor-interacting serine/threonine-protein kinase 2 (RIP2) [2]. Consequent phosphorylation of 

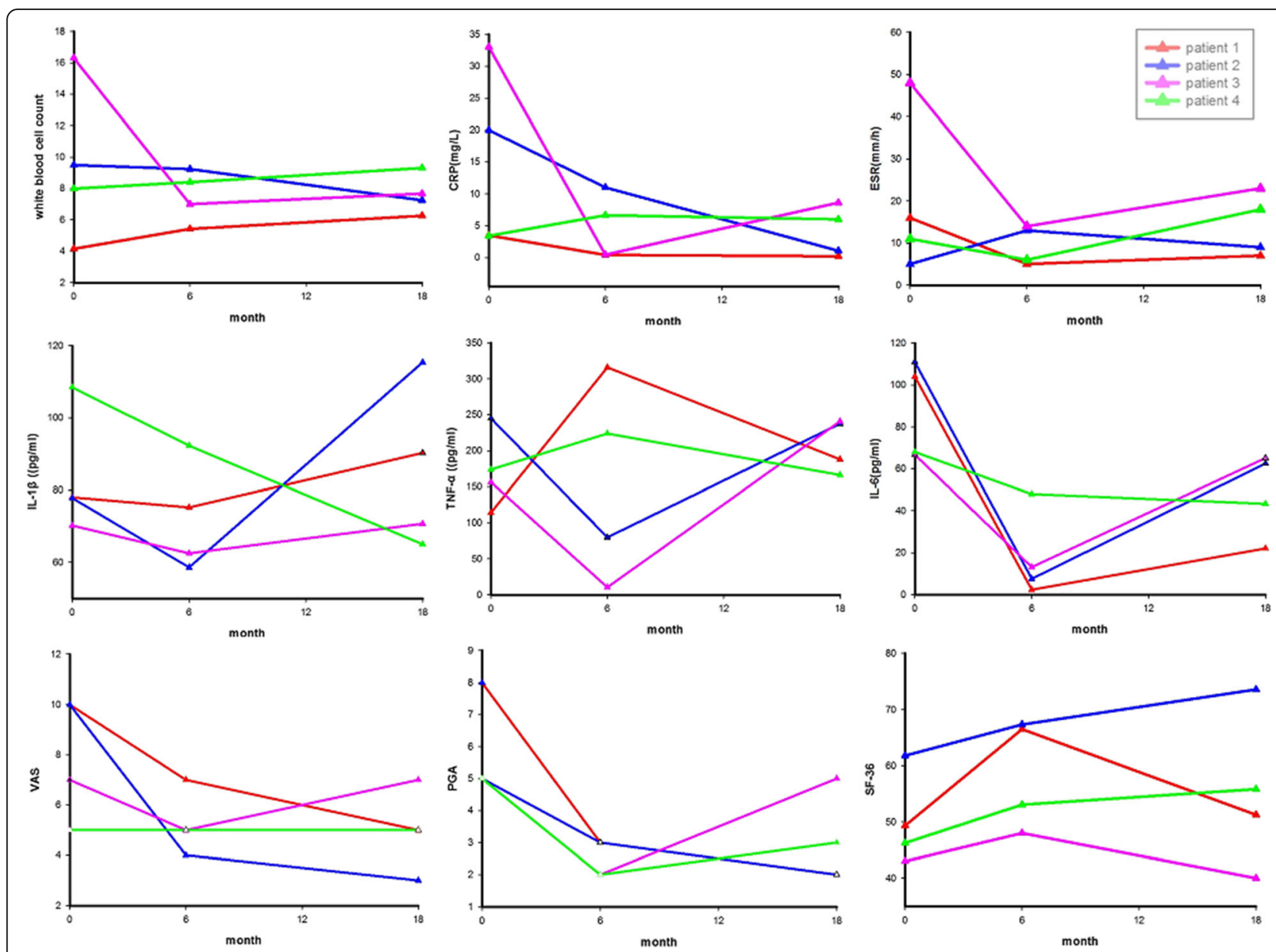

Fig. 2 Changes in disease activity and inflammatory markers of the patients. Overall, WBC, CRP, ESR, IL-1 $\beta, I L-6, V A S$, and PGA decreased, and SF36 increased at the first follow-up of 6 months. TNFa decreased at the first follow-up in patients 2 and 3, but increased in patients 1 and 4 . At the last visit of 18 months, WBC, ESR, and CRP remained normal in all except patient 3, whose ESR and CRP increased to above the normal range. Among all the patients, serum levels of IL-1 $\beta$, TNFa, and IL-6 were higher than those at the first follow-up, except patient 4 . For patients 1 and 2 , VAS and PGA reduced further at the last follow-up, while for patients 3 and 4 , they slightly increased. CRP C-reactive protein, ESR erythrocyte sedimentation rate, VAS visual analogue scale, PGA physician global assessment, SF-36 Short Form-36

RIP2 results in the activation of NF-kB, thus inducing the production of pro-inflammatory cytokines, chemokines, and adhesion molecules to protect the host from infection and participate in the regulation of inflammation [34]. Meanwhile, it was reported that the levels of IL-1 $\beta$, IL- 6 , and TNFa in plasma of BS patients were significantly higher than those of healthy control [35]. Thus, biologic therapy may be beneficial for BS. Recently, biologic agents such as IL-1 blockers, tocilizumab, and TNF $\alpha$ inhibitors have shown promising therapeutic response in refractory patients $[4,7,9,10,29,36]$. Unfortunately, IL-1 blockers are unavailable in China, and the cost of tocilizumab is high. Therefore, TNF $\alpha$ inhibitors are the most commonly used biologic therapy in BS at present in China. IFX, which is a chimeric monoclonal antibody targeted against both receptor-bound and free TNF $\alpha$, appears to be very effective in $\mathrm{BS}$ when combined with low-dose prednisone and low-dose methotrexate [18, 23]. In our literature review, IFX was also well tolerated. In this study, all of the four patients received IFX plus methotrexate, and all achieved clinical remission of skin lesions and polyarthritis rapidly, as well as normalization of ESR and CRP and improvements in VAS, PGA, and SF-36, at the first follow-up of 6 months. Thus, IFX showed a favorable effect on BS.

Despite the potential benefits of the biologics, future development of other potentially therapeutic agents is needed. Intriguingly, NOD2 functions through three signaling pathways, including mitogen-activated protein kinases (MAPK), NF-kB, and autophagy, after interacting with RIP2 and ATG16L1 [2]. From this point of view, the RIP2-specific inhibitors gefitinib and erlotinib which have been used in cancer therapy may be promising in the treatment of BS [37]. Nevertheless, a pilot study 
highlighted the ability of thalidomide, which may contribute to NF- $\kappa \mathrm{B}$ in BS pathogenesis, to improve symptoms in a few BS patients [9].

Since BS is a progressive disorder, diagnosis delay often leads to severe sequelae such as joint deformities and blindness. Hence, early treatment based on early diagnosis is important to avoid physical disability in BS patients. As in our study, patient 2 was diagnosed at an early stage, when he had only arthritis without uveitis and joint deformities. He obtained a complete clinical remission on TNF $\alpha$ inhibitor without the use of systemic corticosteroids. However, his mother, patient 1 in our study, despite a relatively satisfactory response to IFX, had missed the best opportunity for biological agents, and the joint deformities and blindness were irreversible. For BS patients, the main therapeutical goal is to avoid blindness and joint deformities and to improve quality of life as well. Indeed, patients 3 and 4 in our study had a good response to IFX, yet the disease relapsed after they lengthened the interval of medication and discontinued methotrexate. These results suggest that early intervention and regular medication is essential to improve patients' quality of life and disease prognosis.

In conclusion, BS is often misdiagnosed prior to genetic analysis. It should be considered in patients with childhood-onset polyarthritis, uveitis, and dermatitis. Early recognition and effective treatment of BS are very important to avoid the irreversible organ damage (such as loss of vision and joint deformities). TNF $\alpha$ inhibitors such as IFX may be a promising approach in the management of BS patients who have unsatisfactory response to corticosteroids and traditional immunosuppressants. However, due to the sample limitation of our study, more clinical trials are required.

\section{Abbreviations}

BS: Blau syndrome; CRP: C-reactive protein; DMARDs: Disease-modifying antirheumatic drugs; ESR: Erythrocyte sedimentation rate; IFX: Infliximab; IL: Interleukin; NOD2: Nucleotide-binding oligomerization domain containing 2; NSAIDs: Non-steroid anti-inflammatory drugs; PGA: Physician global assessment; SF-36: Short Form-36; TNF: Tumor necrosis factor; VAS: Visual analogue scale; WBC: White blood cell count

\section{Acknowledgements}

The authors would like to acknowledge the patients for their consents to participate in the study.

\section{Authors' contributions}

JC, YL, MZ, DW, YY, WZ, and MS collected the data. JC, YL, DW, and MS analyzed and interpreted the data. JC, YL, MZ, DW, YY, WZ, and MS prepared and revised the manuscript. JC and MS designed the study. All authors read and approved the final manuscript.

\section{Funding}

This work was supported by the National Natural Science Foundation of China (Grant No.81501405; 81501410), Natural Science Foundation of Beijing (Grant No.7192170), the CAMS Initiative for Innovative Medicine (CAMS-I2M) (Grant No. 2017-12M-3-001), and the National Key Research and Development Program of China (Grant No. 2016YFC0901500; 2016YFC0901501).

\section{Availability of data and materials}

All data generated or analyzed during this study are included in this published article.

Ethics approval and consent to participate

Ethical approval was obtained from the Institutional Review Board of the Peking Union Medical College Hospital. Patients provided written informed consents.

\section{Consent for publication}

Informed consents were obtained from all participants.

\section{Competing interests}

The authors declare that they have no competing interests.

\section{Author details}

'Department of Rheumatology, Peking Union Medical College Hospital, Chinese Academy of Medical Sciences \& Peking Union Medical College, Key Laboratory of Rheumatology and Clinical Immunology, Ministry of Education, Beijing 100730, China. ${ }^{2}$ Present Address: Department of Rheumatology, Chongqing Three Gorges Central Hospital, Chongqing 404000, China. ${ }^{3}$ Department of Rheumatology, Peking Union Medical College Hospital, No.1 Shuaifuyuan, Dongcheng District, Beijing 100730, China.

Received: 12 July 2019 Accepted: 26 September 2019

Published online: 12 November 2019

\section{References}

1. Punzi L, Gava A, Galozzi P, Sfriso P. Miscellaneous non-inflammatory musculoskeletal conditions. Blau syndrome. Best Pract Res Clin Rheumatol. 2011;25:703-14

2. Yao Q. Nucleotide-binding oligomerization domain containing 2: structure, function, and diseases. Semin Arthritis Rheum. 2013;43:125-30.

3. Blau EB. Familial granulomatous arthritis, iritis, and rash. J Pediatr. 1985;107: 689-93.

4. Rosé CD, Pans S, Casteels I, et al. Blau syndrome: cross-sectional data from a multicentre study of clinical, radiological and functional outcomes. Rheumatology (Oxford). 2015;54:1008-16.

5. Wang X, Kuivaniemi H, Bonavita G, et al. CARD15 mutations in familial granulomatosis syndromes: a study of the original Blau syndrome kindred and other families with large-vessel arteritis and cranial neuropathy. Arthritis Rheum. 2002:46:3041-5.

6. Xiang $\mathrm{H}$, Zhang $\mathrm{T}$, Chen $\mathrm{M}$, et al. NOD2/CARD15 gene mutation identified in a Chinese family with Blau syndrome. Mol Vis. 2012;18:617-23.

7. Lu L, Shen M, Jiang D, et al. Blau syndrome with good reponses to tocilizumab: a case report and focused literature review. Semin Arthritis Rheum. 2018:47:727-31.

8. Wu D, Shen M. Two Chinese pedigrees of Blau syndrome with thirteen affected members. Clin Rheumatol. 2018;37:265-70.

9. Yasui $\mathrm{K}$, Yashiro $\mathrm{M}$, Tsuge $\mathrm{M}$, et al. Thalidomide dramatically improves the symptoms of early-onset sarcoidosis/Blau syndrome: its possible action and mechanism. Arthritis Rheum. 2010;62:250-7.

10. Sfriso $P$, Caso F, Tognon $S$, et al. Blau syndrome, clinical and genetic aspects Autoimmun Rev. 2012;12:44-51.

11. Imayoshi M, Ogata Y, Yamamoto S. A case of sporadic Blau syndrome with an uncommon clinical course. Case Rep Rheumatol. 2018;2018:6292308.

12. Whyte MP, Lim E, McAlister WH, et al. Unique variant of NOD2 pediatric granulomatous arthritis with severe 1,25-dihydroxyvitamin Dmediated hypercalcemia and generalized osteosclerosis. J Bone Miner Res. 2018:33:2071-80

13. Toral-López J, González-Huerta LM, Martín-Del Campo M, et al. Familial Blau syndrome without uveitis caused by a novel mutation in the nucleotidebinding oligomerization domain-containing protein 2 gene with good response to infliximab. Pediatr Dermatol. 2018;35:e180-3.

14. Nagakura T, Wakiguchi $H$, Kubota $T$, et al. Tumor necrosis factor inhibitors provide longterm clinical benefits in pediatric and young adult patients with Blau syndrome. J Rheumatol. 2017:44:536-8.

15. Ikeda K, Kambe N, Takei S, et al. Ultrasonographic assessment reveals detailed distribution of synovial inflammation in Blau syndrome. Arthritis Res Ther. 2014;16:R89. 
16. Reese T, Villegas L, Wood J, Gotte A. A 21-month-old male with refusal to walk, rash, and weight loss. Arthritis Care Res (Hoboken). 2017;69:286-93.

17. La Torre F, Lapadula G, Cantarini L, et al. Early-onset sarcoidosis caused by a rare CARD15/NOD2 de novo mutation and responsive to infliximab: a case report with long-term follow-up and review of the literature. Clin Rheumatol. 2015;34:391-5.

18. Milman N, Andersen CB, Hansen A, et al. Favourable effect of TNF-alpha inhibitor (infliximab) on Blau syndrome in monozygotic twins with a de novo CARD15 mutation. APMIS. 2006;114:912-9.

19. Becker ML, Martin TM, Doyle TM, Rosé CD. Interstitial pneumonitis in Blau syndrome with documented mutation in CARD15. Arthritis Rheum. 2007;56:1292-4

20. Gedalia A, Khan TA, Shetty AK, et al. Childhood sarcoidosis: Louisiana experience. Clin Rheumatol. 2016;35:1879-84.

21. Sharma SM, Martin TM, Rosé CD, et al. Distinguishing between the innate immune response due to ocular inflammation and infection in a child with juvenile systemic granulomatous disease treated with anti-TNFalpha monoclonal antibodies. Rheumatology. 2011;50:990-2.

22. Inoue $Y$, Kawaguchi Y, Shimojo N, et al. A case of infantile Takayasu arteritis with a p.D382E NOD2 mutation: an unusual phenotype of Blau syndrome/ early-onset sarcoidosis. Modern Rheumatol. 2013;23:837-9.

23. Raiji VR, Miller MM, Jung LK. Uveitis in Blau syndrome from a de novo mutation of the NOD2/CARD15 gene. J AAPOS. 2011;15:205-7.

24. Martin TM, Zhang Z, Kurz P, et al. The NOD2 defect in Blau syndrome does not result in excess interleukin-1 activity. Arthritis Rheum. 2009;60:611-8.

25. Arvesen KB, Herlin $\mathrm{T}$, Larsen DA, et al. Diagnosis and treatment of Blau syndrome/early-onset sarcoidosis, an autoinflammatory granulomatous disease, in an infant. Acta Derm Venereol. 2017:96:126-7.

26. Achille $M$, llaria $P$, Teresa $G$, et al. Successful treatment with adalimumab for severe multifocal choroiditis and panuveitis in presumed (early-onset) ocular sarcoidosis. Int Ophthalmol. 2016;36:129-35.

27. Chauhan K, Michet C. A case of Blau syndrome. Case Rep Rheumatol. 2014; 2014:216056.

28. Naik AU, Annamalai R, Biswas J. Uveitis in sporadic Blau syndrome: longterm follow-up of a refractory case treated successfully with adalimumab. Indian J Ophthalmol. 2018;66:1483-5.

29. Simonini G, Xu Z, Caputo R, et al. Clinical and transcriptional response to the long-acting interleukin-1 blocker canakinumab in Blau syndrome-related uveitis. Arthritis Rheum. 2013:65:513-8.

30. Bravo-Ljubetic L, Peralta-Calvo J, Noval S, et al. Adalimumab therapy for refractory childhood uveitis. J AAPOS. 2013;17:456-9.

31. Glass DA 2nd, Maender J, Metry D. Two pediatric cases of Blau syndrome. Dermatol Online J. 2009;15:5.

32. Cuesta IA, Moore EC, Rabah R, Bawle EV. Blau syndrome (familia granulomatous arthritis, iritis, and rash) in an African-American family. J Clin Rheumatol. 2000:6:30-4.

33. Caracseghi F, Izquierdo-Blasco J, Sanchez-Montanez A, et al. Etanerceptinduced myelopathy in a pediatric case of Blau syndrome. Case Rep Rheumatol. 2011;2011:134106.

34. Boyle JP, Parkhouse R, Monie TP. Insights into the molecular basis of the NOD2 signalling pathway. Open Biol. 2014;4:140178.

35. Aróstegui Jl, Arnal C, Merino R, et al. NOD2 gene-associated pediatric granulomatous arthritis: clinical diversity, novel and recurrent mutations, and evidence of clinical improvement with interleukin-1 blockade in a Spanish cohort. Arthritis Rheum. 2007;56:3805-13.

36. Wouters $\mathrm{CH}$, Maes A, Foley KP, et al. Blau syndrome, the prototypic autoinflammatory granulomatous disease. Pediatr Rheumatol Online J. 2014;12:33.

37. Tigno-Aranjuez JT, Asara JM, Abbott DW. Inhibition of RIP2's tyrosine kinase activity limits NOD2-driven cytokine responses. Genes Dev. 2010;24:2666-77.

\section{Publisher's Note}

Springer Nature remains neutral with regard to jurisdictional claims in published maps and institutional affiliations.

Ready to submit your research? Choose BMC and benefit from:

- fast, convenient online submission

- thorough peer review by experienced researchers in your field

- rapid publication on acceptance

- support for research data, including large and complex data types

- gold Open Access which fosters wider collaboration and increased citations

- maximum visibility for your research: over $100 \mathrm{M}$ website views per year

At BMC, research is always in progress.

Learn more biomedcentral.com/submissions 